\title{
ERME Column
}

Susanne Prediger (President of ERME, TU Dortmund University, Germany) \& Elmar Cohors-Fresenborg (Founding Vice-President of ERME, University of Osnabrück, Germany), Jason Cooper (Weizmann Institute of Science, Rehovot, Israel)

\section{ERME's 20th Anniversary}

In 2018, the European Society for Research in Mathematics Education (ERME) celebrated its 20th anniversary. This article includes a recollection of the first conference in 1998, written by Elmar Cohors-Fresenborg, who was the host of CERME 1 and the founding Vice-President of ERME, and a presentation of a rich anthology, written by the ERME community on the occasion of the anniversary, highlighting 20 years of research.

\section{CERME1 - The First Conference of the European Society for Research in Mathematics Education was held 27-31 August 1998}

Twenty years ago, it was a very exciting time for mathematics education in Europe. During the weekend of 2-4 May 1997, mathematics educators from 16 countries met to discuss what a European society in mathematics education research might look like. The meeting took place in Haus Ohrbeck, near Osnabrück in Germany. Representatives from these 16 countries formed the initial constitutive committee of ERME. It was agreed that the founding philosophy of the society should be one involving Communication, Cooperation and Collaboration throughout Europe.

The formal constitution of ERME took place in a conference scheduled for August 1998. To this First Conference of the European Society for Research in Mathematics Education (CERME1) participants from all over Europe would be invited. CERME1 was organised by the following programme committee: Elmar Cohors-Fresenborg (Germany) as coordinator, Milan Hejny (Czech Republic), Barbara Jaworski (United Kingdom), Joao Pedro da Ponte (Portugal) and André Rouchier (France).

CERME1 was held 27-31 Aug 1998 in Haus Ohrbeck, near Osnabrück, with 120 participants from 24 countries. For the coordinator, it was very important to find substantial support for scholarships to let participants from Middle and East European Countries attend the conference. A generous grant of the "Deutsche Forschungsgemeinschaft" (German National Science Foundation) enabled 22 participants from Middle and East European Countries to attend.

Three sessions at the conference were devoted to considering the new society, its ongoing work and its constitution.

The scientific work was organised in seven thematic groups. Its members worked together on common research. They shared their individual work in order to develop a joint programme of work for the future. It was the intention that each group would engage in scientific debate with the purpose of deepening mutual knowledge about topics, challenges and methods of research in the field. In these ways, the style of the conference deliberately and distinctively moved away from research presentations by individuals toward collaborative group work. 
The results of CERME1 have been published in three volumes of more than 1400 pages. Inge Schwank did the editing work and she also translated the papers into a common layout, which was an incredible amount of work in those days.

\section{From CERME 2 to CERME 11}

Since 1998, ERME kept this spirit of Communication, Cooperation and Collaboration across Europe. The community has grown immensely. CERME11, to be held February 2019 in Utrecht, has attracted a huge number of researchers, and we will be obliged - for the first time - to limit the number of participants to 850 .

During these years since 1998 the exchange about mathematics education research has fuelled substantial developments in the field. These developments are documented in the following book:

\section{Anthology presenting the $\mathbf{2 0}$ years of ERME research}

After three years of preparation, an anthology documenting 20 years of ERME research has appeared: Dreyfus, T., Artigue, M., Potari, D., Prediger, S. \& Ruthven, K. (Eds.) (2018), Developing Research in Mathematics Education - Twenty Years of Communication, Cooperation and Collaboration in Europe", Oxon: Routledge (https://www.routledge.com/Developing-Research-inMathematics-Education-Twenty-Years-of-Communication/Dreyfus-Artigue-Potari-Prediger-Ruthven/p/ book/9781138080294).

The book chapters were written by experienced ERME researchers and were discussed by all CERME participants in 2017. This procedure reflects the ERME spirit of Communication, Cooperation and Collaboration. The ERME community thanks all authors and editors, especially Tommy Dreyfus for taking the lead on a huge, joint enterprise!

Developing Research in Mathematics Education is the first book in the series New Perspectives on Research in Mathematics Education, to be produced in association with ERME. This inaugural volume sets out broad advances in research in mathematics education that have accumulated over the last 20 years through the sustained exchange of ideas and collaboration between researchers in the field.

The chapters provide perspectives on major areas of research in the field on topics that include:

- The content domains of arithmetic, geometry, algebra, statistics and probability.

- The mathematical processes of proving and modelling.

- Teaching and learning at specific age levels from early years to university.

- Teacher education, teaching and classroom practices.

- Special aspects of teaching and learning mathematics, such as creativity, affect, diversity, technology and history.

- Theoretical perspectives and comparative approaches in mathematics education research.

\section{Current news from CERME}

The upcoming CERME11 (https://cerme11.org/) comprises 26 Thematic Working Groups (TWGs), reflecting the growing diversity of the interests in our community. Since the September 2017 issue of the newsletter, we have been introducing these working groups to readers from the mathematics community. To date, we have introduced six of the groups:TWG 14 (University Mathematics Education, September 2017 - Issue 105), TWG 15-16 (Teaching and Learning Mathematics with Technology and Other Resources, December 2017 - Issue 106), TWG 1 (Argumentation and Proof, March 2017 - Issue 107), TWG 12 (History in Mathematics Education, June 2018 - Issue 108) and TWG 9 (Mathematics and Language, September 2018 - Issue 109).

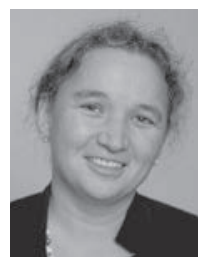

Susanne Prediger has been a full professor for mathematics education research since 2006 at IEEM, the Institute for Development and Research in Mathematics Education at TU Dortmund University. Since 2017, she has been President of ERME (the European Society for Research in Mathematics Education). Her fields of expertise concern design research, conceptual understanding in mathematics, language diversity and mathematics teacher education research.

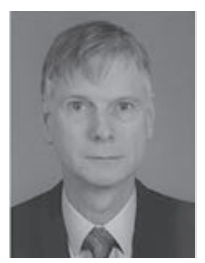

Elmar Cohors-Fresenborg was full professor for mathematics education research, from 1975 until 2013, at the Institute for Cognitive Mathematics (IKM) at the University of Osnabrueck. From 2001 until 2005 he was vice president of ERME, the European Society for Research in Mathematics Education. His fields of expertise concern a cognitive approach to research in mathematics education, especially the role of pupils' and teachers' metacognitive and discursive activities as an indicator of instructional quality in the learning and teaching mathematics.

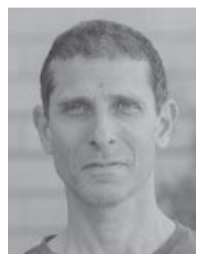

Jason Cooper is a researcher at the Weizmann Institute's Department of Science Teaching. His research concerns various aspects of mathematics teacher knowledge, including roles of advanced mathematical knowledge in teaching, and contributions of research mathematicians to the professional development of teachers. He has been a member of the ERME board since 2015. 